\title{
CONSTELAÇÃO FAMILIAR E A PROMOÇÃO \\ DA ECONOMIA DO MEDO: \\ MAIS UMA DAS MUITAS FORMAS DE VIOLÊNCIA \\ CONTRA A MULHER ${ }^{1}$
}

\section{FAMILIAR CONSTELLATION AND THE PROMOTION OF THE ECONOMY OF FEAR: ANOTHER OF THE MANY FORMS OF VIOLENCE AGAINST WOMAN}

\section{Cláudia Galiberne Ferreira ${ }^{2}$ \\ Heitor Ferreira Gonzaga ${ }^{3}$ \\ Romano José Enzweiler ${ }^{4}$}

Resumo: Neste artigo, analisam-se o conceito, origens e estrutura da constelação familiar, terapia divulgada por Bert Hellinger. Evidencia-se, lado outro, a ligação havida entre constelações familiares e alienação parental, elementos de um mesmo bloco de medidas que perpetuam as violências praticadas contra as mulheres. Sublinha-se o caráter machista da teoria e seu intuito de nulificar o sistema protetivo dos vulneráveis previsto na Constituição Federal e materializado no Estatuto da Criança e do Adolescente, bem como na Lei Maria da Penha. É posta em discussão, também, a cientificidade da técnica aqui debatida, apresentando-se, depois, a teoria central como proposta pelo próprio Hellinger. Neste ponto, sem filtros e sem descontextualizações, são transcritos excertos da extensa obra de Hellinger, confirmando-se as hipóteses lan-

1. Texto gramaticalmente revisado pela inigualável Professora MSc. Maria Tereza de Queiroz Piacentini,da Academia Catarinense de Letras.

2. Advogada. Pós-Graduada em Direito Processual Civil pelo CESUSC/Florianópolis-SC. Autora de vários artigos e livros publicados no Brasil.

3. Graduando em Direito pelo CESUSC/SC. Autor de artigos publicados em sites especializados.

4. Juiz de Direito em Florianópolis/SC. Doutor em Direito pela Univali/SC e pela Universidade de Alicante, Espanha. Pós-doutorando em Direito pela Univali/SC e pela Universidade de Alicante, Espanha. 
çadas de início. Por fim, são postas em xeque as ações do SUS quanto ao financiamento da pseudociência e, ainda, a legitimidade do Judiciário na sua aplicação nos fóruns de justiça.

Palavras-Chave: Constelação familiar. Pseudociência. Poder Judiciário. Financiamento SUS.

Abstract: In this article, concept, origins and structure of the family constellations are analyzed, a therapy disclosed by Bert Hellinger. It is evidenced, nonetheless, the link between family constellations and parental alienation, elements of a block of measures that perpetuate violences practiced against women. The sexist nature of the theory and its intention to nullify the protective system of the vulnerables provided by the Federal Constitution and materialized in the Statute of Children and Adolescents, as well as in the Maria da Penha Law, is underlined. The scientificity of the technique here debated is also put into discussion, followed by the exposition of the central theory as proposed by Hellinger himself. At this point, without filters and without decontextualizations, excerpts from Hellinger's extensive work are transcribed, confirming the hypotheses initially launched. Finally, the actions of the SUS regarding the financing of pseudoscience are challenged, as well as the legitimacy of the Judiciary in its application in justice courts

Keywords: Familiar Constellation. Pseudoscience. Judiciary system. Public health financing (SUS).

\section{INTRODUÇÃO}

A Escola Superior da Magistratura do Estado de Santa Catarina, de maneira inédita no Brasil, abriu neste ano espaço singular para o debate qualificado e científico acerca de um tema candente que se encontra na ordem do dia dos cursos de Direito e fóruns do Brasil e do mundo: as constelações familiares.

O programa levado ao ar pela ESMESC no começo do mês de junho deste ano de 2021, em seu canal YouTube, intitulado "contra o senso comum: ponderações científicas multidisciplinares acerca da ideia de constelação" contou com impressionantes 5.454 visualizações até o momento da revisão final deste texto, menos de 20 dias após sua veicu- 
lação inicial, o que demonstra a pertinência e necessidade de discussão do tema de forma franca e afastada de interesses comerciais, como aqui proposta.

As constelações guardam relação íntima com outra questão-tabu, a alienação parental, igualmente objeto de nossa investigação faz um bom tempo.

Há cerca de sete anos, publicamos na prestigiosa revista da ES$\mathrm{MESC}^{5} \mathrm{o}$ artigo intitulado "Síndrome da Alienação Parental: uma iníqua falácia", texto esse referido em incontáveis trabalhos científicos Brasil afora. Na sequência, juntamente com outros tantos especialistas e pesquisadores brasileiros e espanhóis, estarrecidos com esse estado de coisas, publicamos o livro "A invisibilidade de crianças e mulheres vítimas da perversidade da lei de alienação parental: pedofilia, violência e barbarismo" (FERREIRA; ENZWEILER, 2019), no qual abordamos cientificamente, com ineditismo no Brasil, o tema da alienação parental, que já havia se transformado em lei e começava a ser julgado pelas Cortes brasileiras.

Na época, a expressão "síndrome da alienação parental" (SAP) era quase que totalmente desconhecida pela maioria da população, até mesmo entre os aplicadores do Direito, uma vez que a aprovação da lei que a inseriu no ordenamento jurídico havia ocorrido sem qualquer debate público ou consenso esperado.

$\mathrm{Na}$ verdade, o déficit democrático na feitura de leis que impactam dessa maneira a vida das pessoas, como esta da Lei da Alienação Parental (Lei n. 12.318, de 26 de agosto de 2010 -LAP), tem sido uma constante lamentável nos tempos dessa estranha e-democracia (GOMES, 2018), na qual influencers das redes sociais ditam comportamentos e definem o certo e o errado em absolutamente tudo, do aborto à cor da roupa que deve ser combinada.

A SAP, transmutada em norma pela mágica legislativa operada de maneira pouco ortodoxa, passou a ser utilizada pelos Tribunais, advo-

5. Consulte: https://revista.esmesc.org.br/re/article/view/97. 
gados, psicólogos e partes, sem maior reflexão científica e sem crivo acadêmico qualificado.

A LAP agrada segmentos que estão animados com a "economia do medo" daí gerada, pois a teoria da ameaça engendrada por Gardner, o criador da SAP, permite aos homens mais fácil negociação da divisão patrimonial e definição dos valores da pensão.

Mães e prole, a partir disso, não raro têm tolhidas as chances de organizar e refazer a vida. Vivem à sombra do fantasma do outro, que lhes exige especialmente seu tempo, o qual agora lhe pertence, para sempre. É o mais puro estado da arte da maldade.

A análise dos processos judiciais que tramitam nas varas de família revela o quadro desolador que tomou conta dos fóruns. Genitoras e filhos apavorados com a possibilidade de serem afastados sob a singela acusação de haver "indícios" de ter ela dificultado o convívio da criança com o pai. Basta o genitor se sentir contrariado em quaisquer de suas cambiantes vontades para que isso, de fato, aconteça.

Hoje, em uma quantidade impressionante de litígios de família constam, explícita ou sub-repticiamente, pedidos para que sejam aplicadas às mães, liminarmente, as severas punições previstas na LAP. Um rascunho de laudo, ou por vezes nem isso, é o suficiente para que a criança seja não só afastada da mãe, mas impedida de ter contato com ela por longo tempo. É a teoria da ameaça de Gardner em plena atividade, destruindo vidas e almas, sob o olhar complacente do Estado e seus agentes, pagos para preservar e proteger os vulneráveis.

E assim, a alienação parental - teoria acientífica criada por um perito judicial (Richard Gardner) que defendia especialmente religiosos acusados da prática de pedofilia, teoria esta que vem sendo severamente questionada mundo afora - passou a ser tomada, no Brasil, como verdade incontroversa e incontrastável.

Somente após mais de dez anos, com um rastro de imenso sofrimento infligido a mães e crianças, vítimas da aplicação de tão bárbara "teoria" (e lei), teve início o debate, ainda tímido, sobre sua origem e total ausência de seriedade. 
Alguns poucos corajosos jornalistas ${ }^{6}$ e muitas das abnegadas mães aceitaram desafiar o status quo e passaram a denunciar os abusos cometidos pelo sistema que as pune de maneira tão grotesca. Mães e crianças vitimadas foram ouvidas por congressistas e tentativas legislativas de revogação da lei foram propostas, ainda sem sucesso.

Uma maior consciência acerca da prática de violência contra mulheres e crianças tem permitido que esse debate, aos poucos, floresça. Porém o caminho a ser percorrido para se reverter/revogar o uso e aceitação da LAP será muito árduo, pois solidificado não só no ordenamento jurídico mas no imaginário coletivo, contando com inúmeros simpatizantes, movidos pelos mais diversos e escusos interesses.

Nesse contexto, com enorme preocupação e perplexidade, vimos surgir de forma igualmente sutil e insidiosa a defesa e aplicação em nosso país de outra teoria acientífica, tida como uma "solução" para todos os males da alma (entre eles a cura das "bruxas alienadoras"), uma técnica de resolução e mediação de conflitos, em especial no âmbito familiar.

A chamada "constelação familiar" foi criada por Bert Hellinger, cujo nome é Anton Suitbert "Bert" Hellinger, um ex-seminarista católico que, na segunda grande guerra, alistou- se no exército alemão como soldado, lutando na frente ocidental, onde foi capturado pelos aliados na Bélgica, fugindo dali para, ao final, tornar-se padre, vindo a morar na África do Sul, passando a atuar como missionário junto a tribos zulus. Hellinger deixou a batina e regressou à Alemanha, mudando-se depois para a capital da Áustria, Viena, fixando-se finalmente na Califórnia, Estados Unidos.

A leitura dos textos de Hellinger - leitura que se recomenda, é claro, para que o debate seja franco e honesto - revela, de maneira insofismável, a origem e influências que compõem suas ideias. Ali fica clara a

6. Entre eles, o jornalista Tomás Chiaverini merece uma menção especial, já que pioneiro noenfrentamento desse tema no Brasil. Veja os excelentes artigos por ele publicados: Lei expõe criançasao abuso - em https://apublica.org/tag/alienacao-parental/ e A lei para proteger pais divorciados que expõem suas crianças ao abuso https://brasil.elpais.com/brasil/2017/01/27/ politica/1485522113_903880.html. Acesso em 3/6/2021. 
fixação do autor pelo adultismo, regressão, ocultismo, vidas passadas, xamanismo, panteísmo zulu, hierarquia e ordem ${ }^{7}$.

\section{CONCEITO, ORIGENS E ESTRUTURA DA CONSTELAÇÃO FAMILIAR}

A expressão "constelação" possui, na língua portuguesa, o significado de um grupo de estrelas próximas, de um grupo de pessoas brilhantes ou, ainda, "um conjunto de elementos que formam um todo coerente, ligados por algo em comum" (HOUAISS, 2009, p. 531).

Ao que se sabe, a primeira utilização registrada do termo na literatura científica em língua portuguesa é de Antonios I. Tekzis, no artigo "Constelação Familiar e Esquizofrenia”, publicado no ano de 1987. Neste estudo, estabelece o autor uma relação entre as dinâmicas familiares e a esquizofrenia em pacientes internados em hospitais psiquiátricos. Ali não é ofertada uma clara definição do que se entende por "constelação familiar". Todavia, o termo nitidamente se refere ao "grupo familiar" dos pacientes hospitalizados, nomeando-se essa abordagem focada nas famílias como "Psicologia do Grupo Familiar" (TEKZIS, 1987).

Constitui-se a constelação familiar, de acordo com conceito registrado no site mantido pela Hellinger Schule (Escola Hellinger que é gerida pela esposa de Bert Hellinger, Sophie Hellinger), num método aplicado a um grupo (mas pode ser individual) sob a orientação de um constelador, servindo "às pessoas para descobrir os antecedentes de fracasso, doença, desorientação, dependência ou algo semelhante"».

7. "Muitas pessoas confundem o termo obedecer com ser subserviente ou inferior; outras confundem prepotência e beligerância com liderar. (...) Cada situação é única e as constelações servem para determinar quem deve liderar ou obedecer numa determinada família”. HELLINGER, Bert. A simetriaoculta do amor: por que o amor faz os relacionamentos darem certo. Tradução Gilson C. C. de Sousa.Revisão técnica Esther Frankel, Milton Corrêa e Mimansa Farny. São Paulo: Cultrix, 2008, p. 43.

8. Disponível em: https://www.hellinger.com/pt/pagina/constelacao-familiar/. Acesso em: 1\%/6/2021. 
Em linhas gerais, inicia Hellinger sustentando a existência de um inconsciente familiar (sem descartar os outros dois já consagrados pela literatura: o inconsciente individual e o inconsciente coletivo), que atua sobre todos e cada um dos membros da família.

Para Hellinger, as “ordens do amor” constituem as leis básicas do relacionamento humano - (a) pertencimento ou vínculo, (b) ordem de chegada ou hierarquia, (c) equilíbrio - as quais atuam ao mesmo tempo. Inobservadas as "ordens", instala-se a desarmonia que deságua no fracasso dos objetivos da vida. Portanto, pode-se identificar a "ordem" como o primeiro elemento estrutural da teoria de Hellinger.

De acordo com os constelares, estamos inconscientemente conectados com o destino de nossos antepassados, presos a uma "memória celular", ideia claramente sustentada nas formulações do inglês Rupert Sheldrake, o qual se utiliza das expressões "ressonância mórfica" e "campo morfogenético" (aquela história dos campos de energia com memória que faz com que os macaquinhos localizados em ilhas distantes desenvolvam habilidades semelhantes) para justificar as ligações de nosso destino com o dos que chegaram antes de nós ${ }^{9}$.

Igual fundamentação parece ser utilizada pelos adeptos doutras terapias que guardam semelhança com a Constelação, como Reiki, Qigong e Toque Terapêutico. Todas possuem, conforme Orsi, algo em comum com a Constelação Familiar "e cometem o mesmo erro das teorias 'arqueológicas' que veem astronautas em pinturas pré-históricas. É [numa leitura inocente] uma mistura de perda de contexto e firme vontade de crer" (ORSI, 2019). Logo, identificamos a teoria dos campos morfogenéticos como a segunda inspiração de Hellinger.

O surgimento das constelações possui, ainda e também, forte conexão com o que se denomina de a "nova medicina germânica", promo9. “Campos mórficos são estruturas que se estendem no espaço-tempo e moldam a forma e o comportamento de todos os sistemas do mundo material. Átomos, moléculas, cristais, organelas, células, tecidos, órgãos, organismos, sociedades, ecossistemas, sistemas planetários, sistemas solares, galáxias: cada uma dessas entidades estaria associada a um campomórfico específico". Revista Galileu. Disponível em http:/galileu.globo.com/edic/91/conhecimento1. htm. Acesso em 1\%/6/2021. 
vida pelo ex-médico alemão Hamer, o qual afirmava que toda doença tinha origem num choque emocional, "que vírus e bactérias não causam doenças, que doenças não existem e toda medicina moderna é uma conspiração dos judeus para matar não-judeus". Hamer acabou sendo proibido de clinicar por ter diagnosticado uma criança como portadora de "conflitos" quando, na verdade, ela era portadora de um tumor de Wilms (DAMMERT Krebs, M.,2018 e WILLOW N.D, Dr. K., 2019).

Aos três elementos indicados (ordens, campo morfogenético e nova medicina germânica) juntou-se um quarto aspecto inspirador dos constelares: a biodescodificação, uma "terapia natural" que promete a cura física e emocional, cujo pressuposto reside na descoberta de que toda doença é consequência de nossa forma de pensar ou encarar a vida ${ }^{10}$.

O quinto elemento que forma a estrutura da constelação é o emaranhamento, conceito largamente utilizado por Hellinger ao longo de todos os seus livros. O termo possui inegável inspiração na expressão emaranhamento ou entrelaçamento quântico, empregado pela ciência física e foi, aparentemente, apropriado pela constelação. $\mathrm{O}$ fenômeno que se conhece como emaranhamento ou entrelaçamento quântico, foi inicialmente descrito por Einstein, Podolsky e Rosen, em texto datado de 1935 (HENRIQUE, 2014). Einstein, aliás, referia-se ao fenômeno como ação fantasmagórica à distância. Como exemplifica José Roberto Castilho Piqueira, "duas partículas, elétrons, por exemplo, geradas simultaneamente e em seguida separadas, têm spin não definido em torno de qualquer eixo enquanto nenhuma medida for efetuada. Entretanto, quando o spin de uma delas é medido, assume um certo valor (horário ou anti-horário) e então o spin da outra também se torna conhecido, mesmo que não se tenha acesso a ela" (PIQUEIRA, 2011). Assim, a noção nuclear deste emaranhamento (fenômeno estudado pela mecânica quântica) sugere, basicamente, a existência de fortes correlações entre dois ou mais objetos, mesmo que espacialmente separados por muitos anos-luz.

10. Disponível em: https://kinepharma.es/blog/pt-pt/2019/08/13/que-es-la-biodescodificacion-y-para-que-se-utiliza/ Acesso em 2/2/2021 
É possível também, até pela formação de Hellinger, que o conceito junguiano de sincronicidade esteja presente, mesmo de maneira discreta, na proposta constelar. De acordo com Letícia Capriotti, sincronicidade é "um conceito empírico que surge para tentar dar conta daquilo que foge à explicação causal. Jung diz que 'a ligação entre os acontecimentos, em determinadas circunstâncias, pode ser de natureza diferente da ligação causal e exige um outro princípio de explicação'. A física moderna tornou relativa a validade das leis naturais e assim percebemos que a causalidade é um princípio válido apenas estatisticamente e que não dá conta dos fenômenos raros e aleatórios". Conforme Capriotti, oferece Jung três categorias de sincronicidade: a) a primeira delas refere a "coincidência de um estado psíquico com um evento externo objetivo simultâneo"; b) a segunda define a "coincidência de um estado psíquico com um evento externo simultâneo mas distante no espaço"; c) e, como terceira categoria, a "coincidência de um estado psíquico com um evento externo distante no tempo" (CAPRIOTTI s/d).

Conceituada a constelação e definidos os principais elementos que a inspiram ou sustentam, é possível passarmos ao escrutínio de sua cientificidade.

\section{UMA DISCUSSÃO INADIÁVEL ACERCA DA CIENTIFICIDADE DA CONSTELAÇÃO}

Assim como se dá com a alienação parental, as constelações familiares fazem parte das discussões nos lares e nos fóruns brasileiros com frequência crescente. Está na moda. É suficiente uma busca na internet para localizar muitas centenas de textos, artigos, livros, blogues e ofertas de cursos constelares que se dizem capazes de entender e tratar toda a sorte de doenças e transtornos.

Por dever de honestidade intelectual, enorme cuidado deve ser despendido com a busca das origens, eticidade e cientificidade de qualquer proposta de resolução de problemas e tratamento.

Afinal de contas, sendo a constelação uma técnica aplicada inclusive nos fóruns, muitas vezes com o patrocínio público, como ocorre no 
ambiente SUS, o mínimo que se espera é a certeza de um investimento abalizado, a fim de evitar o esvaziamento da norma constitucional que exige respeito ao uso de nosso dinheiro e aos princípios da eficiência, moralidade e economicidade.

No instigante To explain the world: the discovery of modern science (WEINBERG, 2015), Steven Weinberg narra a história da ciência desde os gregos até os tempos modernos. Um dos principais eixos do texto de Weinberg passa pela discussão dos objetivos e métodos da ciência moderna e o impacto que essa descoberta teve no conhecimento e no impressionante desenvolvimento de nossa civilização. Para o autor, ganhador do prêmio Nobel de física, a espetacular melhoria da qualidade de vida da humanidade é fruto da aplicação rigorosa do método científico. Não é ele, evidentemente, infalível, mas tem sido de enorme utilidade para nos afastar de charlatães e vigaristas, demagogos e populistas.

São os cientistas (e seus métodos), conclui Weinberg, que nos protegem da abundante oferta de ideias carentes de comprovação científica, como o criacionismo, o terra-planismo, a astrologia e, mais recentemente, os movimentos antivacinação.

No "Guia contra mentiras", comenta Daniel Levitin (2019) que a palavra mais acessada no dicionário Oxford foi pós-verdade (post-truth), "definida como um adjetivo relacionado a ou denotando circunstâncias nas quais fatos objetivos influenciam menos a opinião pública do que o apelo à emoção e crença pessoal". E lembra, ao depois, que a pseudociência se caracteriza exatamente pela não objetividade na coleta e tratamento dos dados para a busca da verdade. "Uma teoria", pondera Levitin com inegável propriedade, "não é apenas uma ideia - é uma ideia baseada numa cuidadosa avaliação de evidência. E não uma evidência qualquer - estamos falando de evidência relevante ao assunto em questão, coletada de forma rigorosa e imparcial". A verdade importa, afinal, "pois uma era da pós-verdade é uma era de irracionalidade obstinada, que revoga todos os grandes avanços da humanidade" (LEVITIN, 2019). 
Desta forma, não é qualquer amontoado de ideias e arranjos de palavras empoladas que se transforma em teoria. É preciso ciência (e método) para que a transformação ocorra.

Milenaristas da new age, observa Rosas (2013), fincam sua crença em três pontos centrais, curiosamente em muito assemelhados aos apresentados pelos constelares: a) tudo está conectado entre si e com o universo inteiro; b) todos temos uma energia ou força divina, porque todos somos (parte de) Deus e, portanto, temos um potencial ilimitado e inexplorado; c) a filosofia do Oriente e as religiões das antigas civilizações contêm uma sabedoria universal e eterna (ROSAS, 2013).

As crenças fazem parte de nossa vida, desde sempre. Mas fé não é ciência, e o pior que se pode fazer é tentar "cientificizar" a existência de Deus, por exemplo. $\mathrm{Na}$ atualidade da vida que escolhemos e podemos viver, em não poucas ocasiões se opta pela fé em detrimento da certeza proporcionada pela verdade científica. Pode ocorrer, eventualmente, que o resultado dessa escolha seja favorável à crença, o que sedimenta a esperança na existência de forças inescrutáveis, campos de energia, emaranhados, sincronia, ordem superior natural e biodescodificação capazes de atender as preces dirigidas ao céu (a resposta “acausal"). $\mathrm{Na}$ maioria das vezes, porém, a natureza segue o curso ditado pela segura e rastreável relação de causa e efeito. Quando isso não se verifica é porque, muito provavelmente, não fomos capazes de identificar os elementos da equação, seguindo então pelo caminho do esoterismo para justificar nossa incompreensão do mundo e as complexas relações que há nele.

Eleições dessa natureza, quando afetam somente a um indivíduo, tendem a ser inofensivas. Nestes casos, pode-se pagar o preço da crendice, pois o débito aparece apenas na contabilidade pessoal. Situação completamente diversa, porém, se dá quando são ofertadas ou impostas técnicas carentes de qualquer comprovação científica a terceiros, normalmente vulneráveis pelos mais variados motivos, com graves consequências na vida dessas pessoas.

Em nossa pesquisa acerca da constelação familiar, não foi localizado um único artigo publicado em revista de prestígio e com avaliação 
Qualis/CAPES afirmando (e documentando) a aplicação de métodos científicos para a comprovação da técnica proposta por Hellinger. Em consulta a instituições estrangeiras, igualmente nenhuma publicação que ateste e documente a cientificidade por trás da "teoria constelar" foi encontrada.

Da mesma forma inexiste, para além da bibliografia autorreferenciada, qualquer estudo minimamente denso que comprove, sem se apoiar num quê de obscurantismo, a validade científica (com a utilização de métodos certificados por sociedades especializadas que gozem de respeito internacional) das "teses" morfogenéticas de Scheldrake, da nova medicina germânica de Hamer, da biodescodificação ou do emaranhamento (quântico) aplicado às pessoas, especialmente quando digam respeito a vidas passadas.

Esse o ponto nodal! Constelação familiar - e o conjunto de "teorias" que a sustenta - não possui nenhum traço de ciência, e as ligações costuradas pelos seus defensores entre ciência (que busca a verdade, analisando de forma isenta os fatos e informações disponíveis) e os conceitos constelares simplesmente não possuem sustentação. Como explica o Prof. Steven Novella, neurologista de Yale, citado por Pomeroy (2021), "a gravidade reside na ascensão de um pós-modernismo que sustenta ser a ciência simplesmente uma construção social que defende certos grupos e interesses". No caso específico da medicina "ocidental" baseada em evidências, destaca ele, "dizem os pós-modernistas, trata-se de um produto do colonialismo, que erroneamente relega à obscuridade outras formas de "medicina", como a homeopatia, a medicina tradicional chinesa e os sistemas de cura baseados na religião". E conclui, com preocupação: "A verdade, colhida em pesquisas científicas, é que esses sistemas "alternativos" simplesmente não funcionam. Tratá-los como iguais à medicina baseada em evidências mata pessoas" (POMEROY, 2021).

Antônio Carlos Orsi, no texto "caricatura da ciência: a quântica da prosperidade", comenta: "daria até para escrever um livro inteiro sobre esse hábito recorrente de proponentes de hipóteses esotéricas ou pseudocientíficas, de achar que a ciência de ponta da época em que vivem 
deve, necessariamente, confirmar suas ideias malucas (como fazem com a Física Quântica hoje)”. E prossegue, com precisão:

As saídas usuais são propor um 'campo de consciência' ou trazer o olho de deus para a jogada. Ambas são manobras que destroem as pretensões científicas da área: não há evidência nenhuma de que um "campo de consciência" exista no Universo, seja lá o que isso for, e quando se põe deus no meio, bem, a conversa passa a ser sobre religião, não ciência (ORSI, 2019).

A constelação se utiliza das duas saídas: tenta vestir a capa ornada da ciência e, junto, adiciona uma boa e explícita pitada de religiosidade a essa equação.

O físico Heisenberg, por exemplo, é citado por Hellinger como se fosse o escritor de um almanaque de fácil compreensão, utilizado para emprestar nobreza ao discurso sobre o princípio da incerteza. Nada mais despropositado. Para entender ou mesmo citar Heisenberg, outro prêmio Nobel de física, seria preciso dominar conceitos mínimos de física quântica, o que, obviamente, não é o caso de Hellinger. Por isso, "enquanto o nome de Heisenberg passa a ser cada vez mais reconhecido como o pseudônimo de um fabricante fictício de meta-anfetamina, figuras como Joe Dispenza (autor do imortal best-seller "You Are the Placebo: Making Your Mind Matter"), Gregg Braden ("The Divine Matrix: Bridging Time, Space, Miracles and Belief') e Chopra apresentam documentários e são tratadas por parte da mídia como 'autoridades científicas"” (SHAPPO, 2019).

A partir do argumento de autoridade conquistado com a citação de um prêmio Nobel, por exemplo, e para dar brilho e glamour ao seu jargão new age, inserem os defensores das pseudociências, em seus discursos, alguns "conceitos quânticos", com desmedida imprecisão e não aderência ao contexto real.

Essa é uma prática bastante comum nas ciências sociais, inclusive abundante no Direito. Há incontáveis livros e teses de doutoramento que se vinculam a algum ramo da ciência física, biológica ou matemática para dali inferir algo, digamos, absurdo. 
Nessa mesma linha segue Morilla (2017), para quem as constelações familiares "configuram um perigoso método pseudocientífico", uma vez inexistente qualquer tipo de estudo minimamente rigoroso que avalie sua eficácia, até porque nunca submetida (a técnica) a nenhum protocolo experimental sério, um modelo explicativo da realidade. Pelo contrário, "baseados na ressonância mórfica ou no misticismo quântico, os constelares acreditam unir os seres humanos entre si além do tempo e do espaço, através de uma "energia" completamente alheia à comprovação científica". O perigo se agrava, ainda de acordo com Morilla, "porque qualquer um pode converter-se em 'facilitador', não se requerendo sequer que possuam formação superior como psicólogos". As constelações familiares, conclui, baseiam seu grande êxito na total descarga de responsabilidade do indivíduo: "Ninguém é culpado de seus problemas. Tem câncer de pulmão. Não é porque fumou descontroladamente, é porque seus avós tiveram uma separação desagradável. Não encontra marido? Não é porque está fazendo algo errado, mas porque está expiando um fracasso amoroso de sua mãe quando jovem" (MORILLA, 2017).

De nossa banda, na seara do Direito, é como se afirmássemos que a sentença que julga o estuprador possui transcendência quântica, capaz de impulsionar quarks e léptons para redefinir, em nível subatômico, toda a arquitetura cerebral, a partir da ressonância mórfica causada pelo reposicionamento do córtex pré-frontal, causando um efeito borboleta e, no limite, a saturação e o colapso do universo. Portanto, a única maneira de evitar a ruína do mundo será respeitando e restaurando a ordem e o equilíbrio, colocando o pai de volta no círculo familiar, no seu devido lugar (ápice) pois possivelmente rejeitado e expulso, anteriormente, pela mãe/esposa, a responsável final por todo o acontecido, uma vez ter ela violado a ordem do amor e sua ancestralidade ${ }^{11}$. Isso faz algum sentido?

11. Consulte "Direito Sistêmico" em: https://direitosistemico.wordpress. com/2015/09/22/constelacao-mostra-que-crimes-sexuais-sao-consequencia-da-exclusao-do-pai-da-vitima/?fbclid=IwAR2ehEnQJNYkmG4si- 


\section{A PROPOSTA CONSTELAR PELO PRÓPRIO HELLINGER}

Conceituada a constelação, definidos seus contornos e influências e demonstrada sua acientificidade, é possível analisar o que, de fato, propõe Hellinger em seus livros.

Para tanto, torna-se imprescindível consultar a fonte primária.

Neste item, limitaremos nosso estudo à reprodução fiel do que é exposto por Hellinger, sem emitir qualquer juízo de valor.

Ten Hövel, no prefácio de uma das obras de Hellinger, nos fornece um bom resumo daquilo que é, efetivamente, defendido pela constelação: "Por que é que ele [Hellinger] vê: a) amor em casos de incesto (mas isso é ultrajante!), b) a indignação como uma energia que leva à violência (mas é fundamental lutar contra a injustiça!), c) o respeito pelo masculino apesar de toda a emancipação (como ter respeito pelo masculino em vista de tanto desrespeito pelo feminino?); d) a culpa dos pais adotivos com relação à criança adotada (mas a adoção é um grande ato social!)" (HELLINGER; HÖVEL, 2007, p.8).

O ponto de partida, a premissa primeira da constelação parte da definição do papel, absolutamente preponderante, do homem na família. O homem, afirma Hellinger, "tem precedência sobre a mulher. (...) Depois da separação, os filhos precisam ficar com o progenitor que mais respeite neles o outro. Via de regra é o homem. O homem respeita mais a mulher nos seus filhos do que a mulher respeita neles o marido". (HELLINGER, 2007, p. 39-40). Ademais, noutra passagem, assevera que "os filhos têm os pais que têm. Os pais não podem e nem precisam ser diferentes” (HELLINGER; HÖVEL, 2007, p.24).

Outra das concepções marcantes da proposta de Hellinger refere-se ao tratamento dado a sentimentos como ódio, culpa e perdão no âmbito da extrema violência familiar. Para tanto, relata Hellinger o episódio de uma mãe que era cruel e reiteradamente espancada pelo marido na frente dos filhos, vinculando Hellinger suas conclusões, aqui também, ao protagonismo reservado ao homem, como já antes matizado. $\mathrm{Na}$

2C62A6YbJP-1ZQWmsC6nYGIIqtRCmHMlrzD3DzoHfM. Acesso em $26 / 6 / 2021$. 
sequência, busca ele encadear relações causais, anotando a existência de "uma tentativa fracassada de amar", até porque o pai, mesmo o violador, está a "merecer o devido reconhecimento", pois "privado de alguma coisa". O incesto seria, de acordo com Bert, a tentativa de "reequilibrar o dar e receber na família". Na mesma linha, a mulher que possui uma filha e vem a se casar com outro homem que com elas se preocupa e delas cuida, tem "seus esforços e necessidades diminuídos, desdenhados, ignorados e, às vezes, até ridicularizados. O desequilíbrio entre o dar e o receber desenvolve-se quando um homem dá mais e a mulher recebe mais. Em semelhante situação, a mulher poderia restaurar o equilíbrio se mostrasse gratidão autêntica para com o novo marido". Noutra passagem, tratando do incesto, comenta Hellinger ser ele complicado e revestir diversas formas, devendo-se ter cuidado para não generalizar. Às vezes, destaca, "a violência e o abuso são tão prejudiciais que o aspecto sexual fica em segundo plano: e isso é completamente diferente do incesto cujo móvel fundamental é o sexo. Mas tem razão: já notei que muitas vezes o incesto não passa de uma tentativa fracassada de amar". Desculpabilizando o agressor, sustenta o autor: "alguns terapeutas insistem em ver o agressor como uma besta desumana que força a vítima a saciar seu desejo sexual incontrolável ou suas necessidades emocionais. Eles não captam o contexto mais amplo do sistema familiar". E conclui, quanto ao tema: “em sua forma mais comum, o incesto representa a tentativa de reequilibrar o dar e receber na família - geralmente, mas nem sempre, entre os pais. Se assim for, o agressor foi privado de alguma coisa: por exemplo, o que ele faz pela família não merece o devido reconhecimento. Sob essa forma, o incesto procura corrigir o desequilíbrio entre o dar e o receber". (HELLINGER, 2008, p. 68-9, 83-4).

Noutro trecho, evoca Hellinger o poder ou interferência dos mortos a partir de objetos e o faz, neste caso, por meio do faqueiro da sobrinha-neta do colega de farda, Goring, produzindo um "emaranhado" que nos remete ao "misticismo quântico" (HELLINGER, 2007, p.76). "Emaranhamento", explica Hellinger, "significa que alguém na família retoma e revive inconscientemente o destino de um familiar que viveu 
antes dele. Se, por exemplo, numa família, uma criança foi entregue para adoção, mesmo numa geração anterior, então um membro posterior dessa família se comporta como se ele mesmo tivesse sido entregue. Sem conhecer esse emaranhamento não poderá se ver livre dele" (HELLINGER; HÖVEL, 2007, p.13).

De fato, acredita Bert explicar muitas das tantas contingências que desafiam nossa humanidade e, para tanto, ele volta sempre ao "emaranhamento", definido como aquela situação complexa e confusa de afeto que permeia o sistema familiar.

Mais claramente, e conforme Hellinger, "emaranhamento significa que alguém na família retoma e revive inconscientemente o destino de um familiar que viveu antes dele. Se, por exemplo, numa família, uma criança foi entregue para adoção, mesmo numa geração anterior, então um membro posterior dessa família se comporta como se ele mesmo tivesse sido entregue. Sem conhecer esse emaranhamento não poderá se livrar dele. A solução segue o caminho contrário: a pessoa que foi entregue para adoção entra novamente em jogo. É colocada, por exemplo, na constelação familiar. De repente, a pessoa que foi excluída da família passa a ser uma proteção para aquela que estava identificada com ela. Quando essa pessoa volta a fazer parte do sistema familiar e é honrada, ela olha afetuosamente para os descendentes" (HELLINGER; HÖVEL, 2007, p.11 e 13).

Para os constelares, a conexão com as vidas passadas se dá, também e evidentemente, não apenas através de faqueiros das sobrinhas-netas, mas igualmente pela ligação entre pessoas, vivas ou já falecidas. De acordo com Hellinger, "a injustiça que foi cometida em gerações anteriores será representada e sofrida posteriormente por alguém da família para que a ordem seja restaurada no grupo. É uma espécie de compulsão sistêmica de repetição. Mas essa forma de repetição nunca coloca nada em ordem. Aqueles que devem assumir o destino de um membro excluído da família são escolhidos e tratados injustamente pela consciência do grupo. São, na verdade, completamente inocentes. (...) A consciência do grupo não conhece justiça para os descendentes, mas somente para os ascendentes. (...) Quando alguém é condenado ou ex- 
pulso, isso significa: 'você tem menos direito de pertencer ao sistema do que eu'. Essa é a injustiça expiada através do emaranhamento, sem que as pessoas afetadas saibam disso" (HELLINGER; HÖVEL, 2007, p.14).

Bert dá como exemplo dessa forte e inextrincável ligação a história de um advogado que havia descoberto que sua bisavó fora casada e estava grávida quando conheceu outro homem. Seu primeiro marido morrera no dia 31 de dezembro, com 27 anos, havendo suspeita de que ele tenha sido assassinado. Anos mais tarde, a propriedade do imóvel que ela herdara do marido, que deveria ter ficado para o primeiro filho, acabou sendo destinada ao filho de um segundo matrimônio. Aí a grande injustiça, segundo Hellinger. Esse fato foi o gatilho para que três homens dessa família se suicidassem no dia 31 de dezembro, na idade de 27 anos. "Quando o advogado soube disso, lembrou-se de um primo que acabara de completar 27 anos; e o dia 31 de dezembro se aproximava. Ele foi, então, até a casa dele para avisá-lo. Este já havia comprado um revólver para se matar. Assim atuam os emaranhamentos" (HELLINGER; HÖVEL, 2007, p.14).

No que se refere ao delicadíssimo tema do abuso de crianças, afirma Hellinger existirem dois agressores: o pai, em um primeiro plano, e a mãe. Esta, sentindo-se culpada com relação ao marido, oferece a filha como substituta. Para Bert, deve-se "simplesmente ver o quadro completo. Não bastaria para a criança ficar zangada com o pai; ela tem que ficar zangada também com a mãe. Pelo que pude observar até agora, os pais estão quase sempre em conluio, num pacto secreto, quando se trata do abuso de uma criança" (HELLINGER; HÖVEL, 2007, p.2728, 112).

Na mesma quadra da sexualidade, mas agora quanto ao estupro, refere Hellinger que aquela [a sexualidade] "não perde a sua grandeza. Ela não se torna nefasta nem é afetada por esse ato. (...) Se a mãe quiser colocar em ordem para o filho as consequências negativas de um estupro, ela deveria dizer ao homem: "Você é o pai do nosso filho. Eu o tomo e o respeito como o pai do nosso filho" (HELLINGER; HÖVEL, 2007, p.118-9). 
É esse, em linhas gerais, o contorno do trabalho das constelações como proposto por Bert Hellinger.

\section{O ESTADO E O FINANCIAMENTO DA PSEUDOCIÊNCIA-O SISTEMA ÚNICO DE SAÚDE (SUS) E A POLÍTICA NACIONAL DE PRÁTICAS INTEGRATIVAS E COMPLEMENTARES (PNPIC) $)^{12}$}

Países pobres, é sabido, contam com baixa capacidade de investimento em ciência e tecnologia. Há, normalmente, outras emergências. Poder-se-ia argumentar, não sem razão, que se trata de um círculo perverso, pois sem ciência e sem a incorporação de avanços tecnológicos e inovação, a desigualdade entre nações pobres e ricas tende a aumentar.

No Brasil, onde a disputa por financiamento na área científica é acirrada, o que se espera de agentes públicos responsáveis pela alocação dos escassos recursos é transparência, organização e escolhas criteriosas que resultem em conhecimento e resolução real de problemas.

Também na área da saúde pública, onde falta de tudo, desde medicamentos, salários decentes, leitos hospitalares e até, como se viu recentemente, oxigênio, a situação é igualmente complexa e delicada.

Daí serem de todo pertinentes a preocupação e o alerta externados pela Diretora da Sociedade Brasileira de Física. Sem dinheiro para as ciências sérias e para a medicina baseada em evidências, foram incluídas no Sistema Único de Saúde (SUS), além das 19 já existentes, dez novas "Práticas Integrativas e Complementares", com destaque para a bioenergética, cromoterapia, imposição de mãos, Reiki, florais de Bach, medicina antroposófica, shantala e biodança e, claro, constelação familiar ${ }^{13}$.

De acordo com o Conselho Federal de Medicina, destinou o Ministério de Saúde "ao programa que financia estas práticas pseudocientíficas impressionantes R $\$ 17,2$ bilhões, mais de quatro vezes o orçamento de

12. Disponível em: https://revistaquestaodeciencia.com.br/editorial/2019/09/10/camara-faria-bem-em-rejeitar-lei-que-sacramenta-terapias-alternativas-no-sus. Acesso em 20/6/2021.

13. Portaria $n^{0} 702$, de 21 de março de 2018, do Ministério da Saúde. 
todo o Ministério de Ciência, Tecnologia, Inovação e Comunicações. $\mathrm{O}$ uso de dinheiro público para custear tratamentos que não possuem nenhum fundamento científico deveria ao menos ser discutido de forma ampla com as sociedades científicas"14.

Carlos Orsi, no texto "Constelação familiar, machismo às custas do SUS”, publicado na revista Questão de Ciência, comenta com absoluta propriedade:

No livro Acknowledging What Is: Conversations with Bert Hellinger, o pai da Constelação Familiar afirma que vítimas de abuso sexual infantil que se tornam prostitutas fazem isso por amor inconsciente ao abusador - para carregar a culpa dele. Essas não são "meras" opiniões: são visões paradigmáticas que orientam ações terapêuticas. O paciente ouve que deve encontrar seu lugar adequado no sistema familiar, e esse lugar é definido por uma hierarquia rígida e sexista. Vítimas de abuso sexual ou violência doméstica devem "reconhecer" o laço de amor que as une ao abusador, bem como assumir uma parcela da culpa. Os efeitos disso na cabeça de pessoas que já estão, de algum modo, confusas ou precisando de ajuda - afinal, foram procurar a terapia - pode, para usar um eufemismo, não ser dos melhores. A Constelação Familiar passou a fazer parte do PNPIC em março do ano passado; o Ministério da Saúde divulgou a notícia com indisfarçado orgulho. Grupos que defendem as PICs, achando - ou fingindo achar - que não defendem nada menos inocente do que chá de boldo e rodas de costura para idosos, não levantaram objeção. A Fiocruz até fez um par de vídeos promocionais a respeito, vídeos que curiosamente omitem o papel autocrático do macho na "ordem do amor" propagada pela doutrina. Já há casos de ações judiciais em que a Constelação Familiar foi usada na conciliação entre as partes, principalmente em Varas de Família. Dado o caráter machista e hierárquico da doutrina, não é difícil imaginar para que lado essas “conciliações" pendem. É o seu dinheiro trabalhando. ${ }^{15}$

14. Disponível em: http://www.sbfisica.org.br/v1/home/index.php/pt/acontece/679-um-basta-a-pseudociencia. Acesso em 10/5/2021.

15. Disponível em: https://www.revistaquestaodeciencia.com.br/artigo/2019/12/20/constelacao-familiar- machismo-e-pseudociencia-custas-do-sus. Acesso em 7/6/2021. 


\section{CONSTELAÇÃO E JUDICIÁRIO}

Diante de tantos e tão documentados argumentos dando conta da acientificidade da constelação familiar e, para dizer pouco, da enorme fragilidade de seus fundamentos e, ainda, em face do papel constitucionalmente reservado ao Poder Judiciário, há sentido em permitirmos o financiamento dessa prática com dinheiro público e, nalguns casos, até mesmo exigir que as partes se submetam à "terapia" de Hellinger?

Marino e Macedo (2018) no artigo “A constelação familiar é sistêmica?" questionam, justamente, o porquê de o Poder Judiciário - ao invés de se dedicar à sua função primeira e essencial, que é solucionar problemas de maneira justa e rápida dentro do seu campo de estudo, o que já não é tarefa simples - imiscuir-se na seara do místico e do insondável, descrita ao longo deste texto.

Assim, por exemplo,

o que dizer sobre a inexistência de um código de ética para a atuação dos conciliadores? Quem fiscaliza e regulamenta sua atuação? Como se dá a capacitação dessas pessoas? "Como se garante que as questões emocionais dos juízes não influenciarão sua conduta na própria constelação e no processo jurídico? O sistema judiciário não estaria impondo uma técnica que tem influência religiosa cristã em detrimento das outras crenças religiosas? Sendo o Brasil um país laico, sua Constituição garante essa liberdade de escolha? O Estado, por meio do sistema judiciário, pode interferir na privacidade de seus cidadãos em prol da redução de processos jurídicos promovendo acordos influenciados pela posição de poder dos juízes que aplicam a técnica? O sistema judiciário - quando incentiva juízes a atuarem no fórum como consteladores e representantes da lei - pode assegurar que os cidadãos terão livre-arbítrio para decidir se desejam ou não fazer acordo? E os cidadãos podem se assegurar que seus direitos foram preservados? Os fóruns do Brasil não estariam se transformando em espaços colonizadores de uma suposta religião correta? Os fóruns de juízes consteladores não estariam se transformando em palcos de desigualdade de gênero entre homens e mulheres, na medida em que a técnica acredita que a mulher deve seguir os passos do homem e que possui um papel específico de "guardiã do bem-estar da família" enquanto que o homem deve se responsabilizar por sua segurança externa? As mulheres podem 
confiar na isenção dos juízes consteladores ao incentivar acordos? Como o Estado garantirá que os direitos das mulheres serão preservados? ${ }^{16}$

E, acrescentamos, quem será responsabilizado (responsabilidade objetiva, sem dúvidas) em caso de eventuais e potenciais problemas daí derivados? Como compatibilizar esses "serviços" com o Código de Defesa do Consumidor?

Com efeito, as constelações estão na moda em todo o mundo, sendo levadas a cabo por pessoas desqualificadas para trabalhar em tal contexto e, portanto, não disciplinadas por nenhum código deontológico ou conselho profissional. Assim, não há a mínima proteção ao consumidor submetido à terapia, uma vez que o que se está oferecendo é um produto sob a forma de ato médico (FASCE, 2015).

São esses, destaque-se, apenas alguns dos muitos questionamentos que se poderiam apresentar contra a presença da constelação familiar nos fóruns brasileiros.

\section{CONCLUSÕES}

O Tribunal de Justiça do Estado de Santa Catarina publicou, no final do mês de janeiro de 2020, os trágicos dados estatísticos relacionados ao feminicídio no Estado. Ao todo, diz a matéria, "foram 57 assassinatos de mulheres motivados por discriminação de gênero no âmbito doméstico", ou seja, mais de um assassinato por semana. "Já o número de feminicídios tentados chegou a 160 no mesmo período". Durante o ano de 2019, "foram concedidas pela justiça catarinense mais de 16.000 medidas protetivas", o que revela um espantoso aumento de $28 \%$, se comparados os dados com os do ano passado. ${ }^{17}$

16. Disponível em: http://pepsic.bvsalud.org/scielo.php?script=sci_arttext\&pid=S0104-78412018000300003. Acesso em 9/2/2021.

17. Disponível em: https://www.tjsc.jus.br/web/imprensa/-/media-de-um-feminicidio-por-semana-em-sc-durante-2020-exige-pronta-acao-da-justica?inheritRedirect $=$ true $\&$ redirect $=\% 2 \mathrm{~F}$. Acesso em 09/02/2021. 
De acordo com o Instituto Avon - Data Popular, "aproximadamente 52 milhões de brasileiros conhecem pelo menos um homem que já tenha sido violento com a parceira. Ainda assim, somente $16 \%$ dos homens assumem ter cometido violência contra a mulher, pois na concepção deles, fazer sexo contra a vontade, humilhar em público, impedir de sair de casa ou de vestir determinada roupa não é uma forma de violência" (CONTE, 2021).

Leis como a conhecida Maria da Penha trouxeram um pouco de alento às esposas e companheiras vítimas da agressividade insana. Como reação, mas de forma mais intensa, a lei da alienação parental e "terapias" como a constelação familiar fizeram os poucos direitos conquistados pelas mulheres retroceder à estrutura da família medieval.

A violência sexual, os feminicídios, as agressões demonstram, à saciedade, o quão cruel, perverso e descolorido tornou-se o mundo para as mulheres e meninas no Brasil.

$\mathrm{O}$ "sistema constelar" apresentado por Hellinger é assumida e fundamentalmente machista, e sua lógica parte da anulação absoluta daqueles familiares de segunda categoria - mãe, filhas e filhos -, o que contribui para que mais mulheres sejam espancadas na frente das crianças e se sintam culpadas por não terem dado ao marido aquilo que ele merecia. É isso que afirma a "terapia" calcada na "ordem do amor", que se dá através de relações fundadas numa espécie de "contabilidade" (o dar e o receber), na gratidão da mulher para com o marido, o que explicaria, então, o "equilíbrio" que deve presidir a vida familiar. Esse equilíbrio, espantosamente, deve inclusive ser buscado praticando a maldade. Nas palavras de Hellinger: "Um homem que magoa a mulher, dizendo-lhe talvez algo como 'você é igualzinha à sua mãe'. Se a mulher fica muito sentida, ela tem de feri-lo também para restaurar o equilíbrio e dizer-lhe algo que o magoe. Essa é a lição que muitos não entendem: o equilíbrio precisa ser restaurado tanto no bem quanto no mal" (HELLINGER; HÖVEL, 2007, p.44).

Estamos presenciando, de fato e atônitos, um verdadeiro massacre de gênero, e os que deveriam promover a segurança dos vulneráveis se calam e se omitem. 
A constelação familiar, objeto deste estudo, pretende ser o outro lado da história das famílias, contrapondo-se às verdades científicas. Todavia, só existem dois lados quando há evidências que os embasem. A constelação não se sustenta em evidências, mas no poder da sugestão. Podemos ter opiniões próprias, inclusive sobre a fé. Mas não podemos, para defendê- las, deformar a ciência e a verdade, porque, como aqui já afirmado, a verdade importa, pois está umbilicalmente ligada à ética (ECO; MARTINI, 2000, p.153). Essa "pós-verdade" nos está levando pelo caminho da irracionalidade obstinada e aniquilando os melhores avanços arduamente conquistados pela humanidade.

Com premissas falsas, misticismo e pseudociência, somos capazes de criar explicações fantásticas, mas destituídas de qualquer utilidade, quando não perigosas.

Ao longo de nossa história, já acreditamos que sacrifícios humanos aplacariam a fúria dos deuses e auxiliariam na colheita, que a sangria era benéfica à saúde, que queimar mulheres acusadas de bruxaria faria com que suas almas fossem destruídas, que a terra era plana, que Deus criou o mundo e nos criou e que, portanto, a tese evolucionista é falsa. Muitos inocentes, por conta da ignorância e maldade, foram mortos devido à histeria coletiva que de tempos em tempos nos assombra.

Podemos acreditar que o emaranhamento de Hellinger seja responsável pelo nosso destino, que os fatos da vida (um bom emprego, pais carinhosos, casamento infeliz, traição do cônjuge) são decorrência das ligações que temos com os mortos através de um faqueiro, por exemplo, e que a adoção de crianças [um dos gestos de amor mais maravilhosos e completos de que somos capazes como espécie] vulneráveis e eventualmente violentadas seja, para a concepção constelar, um equívoco. É possível acreditar, como quer Bert Hellinger, que quando uma criança é vítima de violência e abuso sexual, há dois agressores - o pai e a mãe - que agem em conluio, por meio de um pacto secreto, e que, portanto, a criança deva ficar zangada com ambos, uma vez que a mãe oferece a filha porque não é ela mulher suficiente para o marido. Portanto, para Bert, o terapeuta deve se ligar ao agressor a fim de restabelecer o equilíbrio familiar. Em sua forma mais comum, comenta ele, o incesto repre- 
senta a tentativa de reequilibrar o dar e receber na família - geralmente, mas nem sempre, entre os pais. Podemos assim, adotando as ideias de Hellinger, revitimizar a criança, destruindo suas ligações de afeto com a mãe, aquela que a salvou da barbárie paterna. Temos o supremo poder, enfim, de matá- la deixando-a viva, retirando dela qualquer chance de uma vida plena e feliz. Ainda nesse tema doloroso e repugnante, é possível seguir Hellinger e afirmar que, mesmo no estupro, a sexualidade não perde sua grandeza, devendo a mãe, se quiser restabelecer a ordem, dizer ao estuprador ser ele o pai do "nosso filho", respeitando-o como "o pai do nosso filho".

Temos com Hellinger, portanto, a oportunidade de retirar das vítimas (mães, filhas e filhos) os últimos resquícios de sua dignidade humana.

Lado outro, o ser humano está apto, também, a rechaçar quaisquer propostas delirantes e patológicas que subvertam as conquistas civilizatórias e inflijam dor e sofrimento aos já desdenhados pela sorte. É também capaz de perceber a obscenidade por trás da tentativa de "normalização" de práticas como o estupro e o incesto, aceitas por Hellinger, mas rejeitadas por qualquer pessoa sã e que tenha um mínimo de respeito pelo outro.

Podemos, ainda, acreditar que o curioso caso dos suicídios dos homens de uma dada família - todos ocorridos no dia 31 de dezembro à idade de 27 anos, narrado por Hellinger e reproduzido neste ensaio, se efetivamente comprovado - foi obra do "emaranhamento" constelar, quando a bisavó de alguém deixou de herança o imóvel ao filho "B" quando, em princípio, o herdeiro seria o filho "A". Essa dita "injustiça terrível" teria desencadeado uma maldição inimaginável, pois durante gerações os homens da família, incomodados com o fato, acabaram se suicidando.

Mas somos também capazes de deixar de lado essa fantasia espectral e verificar que apenas no Brasil, todos os dias, cerca de 30 pessoas tiram a própria vida. Esse número é maior do que as mortes das vítimas de AIDS e de diversos tipos de câncer. De cada 100 brasileiros, 17 já pensaram, ao menos uma vez, em tirar a própria vida. Não se trata de uma decisão pessoal ou uma expressão do livre-arbítrio, nem de um ato 
de coragem. O que ocorre, na verdade, é que as "pessoas que concretizam esse ato estão passando quase que invariavelmente por uma doença mental que altera, de forma radical, a sua percepção da realidade. Quem toma esse tipo de atitude sempre está muito cheio de sofrimento e acaba ficando cego por conta disso. Não enxergam nenhuma solução possível no momento. Então, o tratamento da doença mental é um dos pilares mais importantes de prevenção" (CONTE, 2014).

É possível, se se quiser, acreditar que o suicídio de várias pessoas de uma mesma família tenha ligação com a bisavó deles, por conta de um imóvel de herança. Mas isso faz, realmente, algum sentido? Pode-se, entretanto, optar pela verdade científica e consultar dados estatísticos e médicos a respeito da saúde mental das pessoas e verificar que há doenças, como a depressão, que possuem componentes genéticos (CRAFT; PERNA, 2004) o que pode, eventualmente, levar ao suicídio. Isso é ciência.

Podemos aceitar que tumores não existem, que câncer é bom, que as doenças são fruto de choques emocionais, que vírus e bactérias não causam mal algum, que a cura de toda e qualquer enfermidade está no nosso agir, pensar e querer, isto é, está em nós mesmos. O médico Hamer, criador da "nova medicina germânica", disse isso aos pais da pequena Olivia, de apenas 6 anos de idade, portadora de um tumor de Wilms, um câncer renal comum em crianças. Hamer afirmou à família de Olivia que ela não tinha um tumor, mas "conflitos".

Temos o poder de acreditar em fantasmas, e até de criá-los em nossa mente, mas também temos condição de optar pelo mundo dos pensamentos coerentes, racionais e saudáveis.

O que não podemos tolerar, em nome da "flexibilidade dos valores", é que se violentem mais mulheres e crianças impunemente, que o próprio Estado patrocine terapias pseudocientíficas ineficientes e, muitas das vezes, perigosas. O que se mostra inadmissível é assistir o SUS gastando dinheiro público ao patrocinar terapias sem qualquer validade científica, deixando a ciência verdadeira sem recursos para pesquisa e inovação. O que impressiona é verificar as terapias constelares tomando conta, inclusive, dos fóruns judiciais. 
Finalmente, o que estarrece é perceber a invisibilidade das vítimas, a empáfia dos agressores e a insensibilidade dos que, devendo falar e agir, emudecem e paralisam.

\section{REFERÊNCIAS BIBLIOGRÁFICAS}

ARANTES, José Tadeu. Revista Galileu. Disponível em http://galileu. globo.com/edic/91/conhecimento1.htm. Acesso em 1\%/2/2021.

CAPRIOTTI, Letícia. Jung e sincronicidade: o conceito e suas armadilhas. Disponível em: http://www.symbolon.com.br/artigos/jungesicroni2.htm. Acesso em 3/5/2021.

CONTE, Juliana. É possível prevenir o suicídio. 2014. Disponível em: https://drauziovarella.uol.com.br/psiquiatria/e-possivel-prevenir-o-suicidio/. Acesso em 10/2/2021.

CONTE, Juliana. Vítimas de violências sexual devem procurar serviços de saúde mesmo muito tempo após o ocorrido. Revisado em

7/4/2021. Disponível em: https://drauziovarella.uol.com.br/mulher-2/vitimas-de-violencia-sexual-devem-procurar- servicos-de-saude-mesmo-muito-tempo-apos-o-ocorrido/. Acesso em 10/2/2021.

CRAFF, Lynette L. PERNA, Frank M. The benefits of exercise for the clinically depressed. The primary care companion to the jornal of clinical psychiatry. Disponível em: https:/www.ncbi.nlm.nih.gov/pmc/articles/PMC474733/

DAMMERT KREBS, M. (2018). El cáncer es bueno... y las enfermedades no existen!: una introducción a las 5 Leyes Biológicas descubiertas por el Dr. Ryke Geerd Hamer. [Kindle Android version]. Retrieved from Amazon.com.

ECO, Umberto. MARTINI, Carlo Maria. Em que crêem os que não crêem? 4 ed. Rio de Janeiro: Record, 2000.

FASCE, Angelo. Constelaciones familiares: lo que no se cuenta. La venganza de Hipatia. Novembro de 2015. Disponível em: https:// lavenganzadehipatia.wordpress.com/2015/11/01/constelaciones-fa- 
miliares-lo-que-no- se- cuenta/\#: :text=Las $\% 20$ constelaciones $\% 20$ familiares $\% 20 \mathrm{de} \% 20$ Hellinger,supervisadas $\% 20$ p or $\% 20$ ninguna $\% 20$ instituci $\% \mathrm{C} 3 \% \mathrm{~B} 3 \mathrm{n} \% 20$ sanitaria. Acesso em 7/3/2021.

FERREIRA, Cláudia Galiberne. ENZWEILER, Romano José. A invisibilidade de crianças e mulheres vítimas da perversidade da lei de alienação parental: pedofilia, violência e barbarismo. Florianópolis: Conceito Editorial, 2019.

FERREIRA, Cláudia Galiberne. ENZWEILER, Romano José. Síndrome da alienação parental: uma iníqua falácia. Revista da Esmesc. Vol. 21, n. 27. Florianópolis: 2014.

GOMES, Wilson. A democracia no mundo digital: história, problemas e temas. São Paulo: Edições SESC SP, 2018.

HELLINGER, Bert. A Simetria Oculta do Amor: por que o amor faz os relacionamentos darem certo. Tradução Gilson César Cardoso de Sousa. Revisão técnica Esther Frankel, Milton Corrêa e Mimansa Farny. São Paulo: Cultrix, 2008.

HELLINGER, Bert. HÖVEL, Gabriele Ten. Constelações familiares: o reconhecimento das ordens do amor. Conversas sobre emaranhamentos e soluções. Tradução Eloisa Giancoli Tironi, Tsuyuko Jinno-Spelter. São Paulo: Cultrix, 2007.

HELLINGER, Bert. Ordens do amor: um guia para o trabalho com constelações familiares, $3^{\mathrm{a}}$. reimpressão da $1^{\mathrm{a}}$ edição de 2003 . Tradução Newton de Araújo Queiroz. Revisão técnica Heloísa Giancoli Tironi, Tsuyuko Jinno-Speltez. São Paulo: Cultrix, 2007.

HENRIQUE. Franciele Renata. O paradoxo de Einstein-Podolsky-Rosen. Mecânica Quântica A. Junho de 2014. Disponível em: http://www. ifsc.usp.br/ strontium/Teaching/Material2014- 1\%20SFI5774\%20Mecanicaquantica/Seminario\%20-\%20Franciele\%20-\%20Einstein- Podolski-Rosen.pdf. Acesso em 4/2/2021.

LÉVI-STRAUSS, C. Les Structures Élementaires de la Parenté. Paris, 1949. 
LEVITIN, Daniel J. O guia contra mentiras: como pensar criticamente na era da pós verdade. Tradução Leonardo Alves. São Paulo: Objetiva, 2019.

MARINO, Sueli. MACEDO, Rosa Maria S. Macedo. A constelação familiar é sistêmica? Nova perspectiva sistêmica. Vol. 27, n. 62. São Paulo, set./dez. 2018.

MORILLA, Sergio Garcia. Constelaciones familiares, un peligroso método pseudocientífico. Psyciencia. Fevereiro2017. Disponível em : https:/www.psyciencia.com/constelaciones-familiares-un-peligroso-metodo- pseudocientifico/. Acesso em 22/6/2021.

ORSI, Antonio Carlos. Caricatura de ciência: a quântica da prosperidade. Revista Questão de Ciência. Outubro 2019. Disponível em https://revistaquestaodeciencia.com.br/apocalipse- now/2019/10/25/caricatura-de-ciencia-quantica-da-prosperidade. Acesso em 15/6/2021.

PIQUEIRA, José Roberto Castilho. Teoria quântica da informação: impossibilidade de cópia, entrelaçamento e teletransporte. Revista Brasileira de Ensino da Física. vol.33, n.4. São Paulo Oct./Dec. 2011. Disponível em: http://dx.doi.org/10.1590/S1806-11172011000400003. Acesso em 3/6/2021.

POMEROY, Ross. Postmodernism: "The Ultimate Sour Grapes of Science Deniers". Disponível em: https://www.realclearscience.com/ articles/2021/02/04/postmodernism_the_ultimate_sour_gra pes_of_ science_deniers_658359.html. Acesso em: 9/6/2021.

ROSAS. Luis Javier Plata. Mitos del siglo XXI: charlatenes, gurús y pseudociência. Ciudad de México: D. R. Editorial Lectorum S.A., 2013.

SCHAPPO, Marcelo Girardi. Ciência de verdade passa longe da "feira quântica". Revista Questão de Ciência. Dezembro 2019. Disponível em https://revistaquestaodeciencia.com.br/artigo/2019/12/04/ciencia-de-verdade-passa-longe-de- feira-quantica. Acesso em 6/4/2021. 
TEKZIS, A. I. Constelação familiar e esquizofrenia. Arquivos de Neuro- -Psiquiatria,45(3), 276-280.1987.https://www.scielo.br/j/anp/a/ Yv6DCy4RvxkFpQZbjZmMyXP/?lang=pt. Acesso em 1\%/6/2021.

VILLAS BÔAS, Orlando. A arte dos pajés: impressões sobre o universo espiritual do índio xinguano. São Paulo: Editora Globo, 2000.

WEINBERG, Steven. To explain the world: the discovery of modern science. London: Penguin, 2015.

WILLOW N.D, Dr. K. (2019). German New Medicine - Experiences in Practice: An Introduction to the Medical Discoveries of Dr. Ryke Geerd Hamer [Kindle Android version]. Retrieved from Amazon.com.

Recebido em: 30/06/2021

Aprovado em: 01/07/2021 